\title{
Localized Metastasis
}

National Cancer Institute

\section{Source}

National Cancer Institute. Localized Metastasis. NCI Thesaurus. Code C162650.

The focal spread of a malignant tumor in a single anatomic site. 